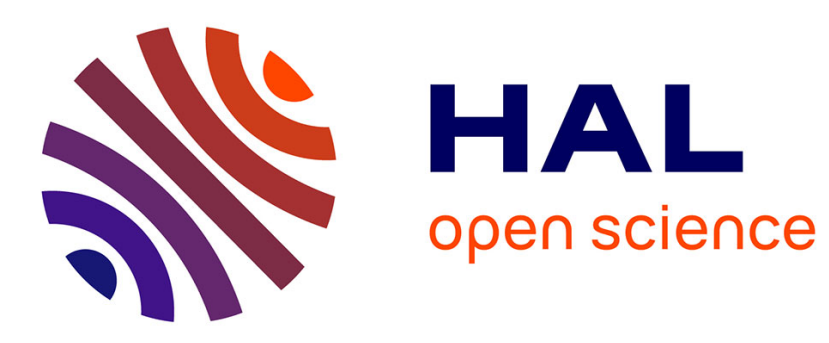

\title{
Pulse-Jet Bag Filter Performances for Treatment of Submicronic and Nanosized Particles from Waste Incineration
}

R. Boudhan, Aurélie Joubert, K. Gueraoui, S. Durécu, D. Venditti, D. T. Tran, Laurence Le Coq

\section{To cite this version:}

R. Boudhan, Aurélie Joubert, K. Gueraoui, S. Durécu, D. Venditti, et al.. Pulse-Jet Bag Filter Performances for Treatment of Submicronic and Nanosized Particles from Waste Incineration. Waste and Biomass Valorization, 2018, 10.1007/s12649-017-9858-4 . hal-01531936

\author{
HAL Id: hal-01531936 \\ https://hal.science/hal-01531936
}

Submitted on 21 Aug 2019

HAL is a multi-disciplinary open access archive for the deposit and dissemination of scientific research documents, whether they are published or not. The documents may come from teaching and research institutions in France or abroad, or from public or private research centers.
L'archive ouverte pluridisciplinaire HAL, est destinée au dépôt et à la diffusion de documents scientifiques de niveau recherche, publiés ou non, émanant des établissements d'enseignement et de recherche français ou étrangers, des laboratoires publics ou privés. 


\title{
Pulse-Jet Bag Filter Performances for Treatment of Submicronic and Nanosized Particles from Waste Incineration
}

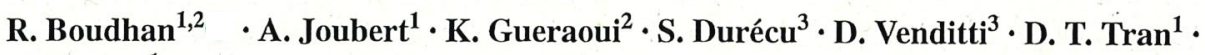 \\ L. Le $\operatorname{Coq}^{1}$
}

\begin{abstract}
The main objectives of this study were to develop an experimental set-up to perform clogging/ unclogging tests on a single baghouse fabric filter, and to evaluate its filtration performance regarding submicronic and nanosized particles, for operating conditions as close as possible to those found in real-scale waste incineration facilities in terms of gas flowrate, temperature and humidity, inlet concentrations for both the dust and the sorbent, the pressure and duration of the cleaning pulse-jet. The performances of a bag filter during several clogging/ unclogging cycles were evaluated regarding the filtration of a submicronic aerosol whose particle size distribution is representative of nanowaste incineration emissions at the boiler outlet. In order to reproduce the real operating conditions in the flue gas treatment line, the airflow and the bag filter were heated to $150^{\circ} \mathrm{C}$ and the filtration unit was insulated. The water content was maintained in the airflow in the range of $10-12 \%$ (i.e. $3 \%$ relative humidity) by water injection and the filtration velocity throughout the bag filter was $2 \mathrm{~cm} / \mathrm{s}$. Moreover, a mix of suspended particles of activated carbon and sodium bicarbonate, used in flue gas treatment lines mainly for dioxin/furan and acid gas removal, were generated simultaneously with the submicronic aerosol. The results showed a high total particle collection efficiency of the bag filter, which increased rapidly
\end{abstract}

1 Ecole des Mines de Nantes, GEPEA, CNRS, UMR 6144 , 44307 Nantes cedex 03, France

2 Faculté des Sciences de Rabat, B.P. 1014 RP, Rabat, Morocco

3 TREDI, Service R\&D - Groupe Séché Environnement, 54505 Vandœuvre-lès-Nancy, France with clogging from 98 to $99.99 \%$. Particles with a diameter of $90 \mathrm{~nm}$ were the most penetrating across the filter, for which the fractional efficiency reached a minimum value of $97.5 \%$. These results demonstrated the effectiveness of bag filters for submicronic and nanosized particle filtration in industrial conditions for the treatment of waste incineration fumes.

Keywords Waste incineration - Filtration performances · Bag filter $\cdot$ Clogging/unclogging cycle $\cdot$ Submicronic and nanosized particles

\section{Introduction}

According to Roco et al. [1], the number of discoveries, inventions, nanotechnology workers, R\&D funding programs, and markets increased by an average annual rate of $25 \%$ between 2001 and 2008 . As a consequence, the global market for products incorporating nanotechnology reached about $\$ 254$ billion in 2009 . These statistics show the immense quantity of manufactured nanomaterials that has been introduced into the markets over the last 10 years. To date, there is no special approved procedure for the waste management of nano-objects at their end of life, mainly because the current regulations do not consider the typical nano-specificity of such emerging products. The insufficient studies about the impact of nanowaste on the environment and especially the lack of understanding about the behavior of free nanoparticles in the atmosphere are serious problems facing the world. As a precautionary measure, many relevant factors and dimensions must be taken into account in order to make appropriate and responsible decisions about the application of nanotechnology. For example, the study of nanoparticle 
toxicity has revealed that the nanosize characteristic of a particle may be determinant in its potential toxicity whatever the chemical composition; in other words, nanoparticles may be toxic even if larger particles constituted with the same elements are not [2].

Due to the lack of regulation for nanowaste at its end of life, it may be incinerated. Tran et al. [3, 4] studied the incineration of three different nanowastes at laboratory scale and quantified the emission of nanoparticles after the laboratory-scale incineration unit. They concluded that nanowaste incineration may lead to the emission of nanoparticles in the post-combustion zone, towards the flue gas treatment line.

With electrostatic precipitators, bag filters are among the most efficient dry technologies for particle removal implemented in flue gas treatment lines. The bag filter units are usually constituted of several cylindrical bags in which a particulate cake is formed during the filtration process and then the bags are periodically unclogged with an on-line pulse-jet method. To the best of our knowledge, most studies using bag filters for gas purification have mainly dealt with particles larger than $0.2 \mu \mathrm{m}$ in diameter [5-10] but none has focused on the nanosize particle range. Recently, Förster et al. [11] have investigated bag filter medium performance during nanoparticle filtration of waste incineration plants, but the filtration experiments were realized with filter simples in flat geometry. Most of the aerosols tested for filter clogging were limestone, $\mathrm{NaCl}, \mathrm{PVC}$, or glass fiber. There is only a single study about bag filter performances using particles representative of waste incineration raw fumes [11] because of few studies are available on submicron particle emissions from incineration plants [12]. Cahill et al. [13] clearly showed that dust properties can affect filter efficiency. In addition to the influence of particle properties on filtration performances, filtration efficiency changes during the process, which means that clean and used filters do not have similar performances. A few studies have investigated used filters during clogging [8-10] but the majority has focused on clean fibrous filters [14]. Furthermore, according to Kim et al. [15], only a little information is available about the filtration of nanoparticles, particularly using bag filters.

The present study focused on the filtration performances of bag filters used for the treatment of flue gas (raw fumes) from waste incineration. The study aimed to quantify the filtration performances of a pulse-jet bag filter at the laboratory-scale regarding submicronic particles with a nanosized fraction during clogging/unclogging cycles. The bag filter was operated in realistic conditions, as close as possible to those found in flue gas treatment lines of waste incineration, in terms of temperature, humidity, filtration velocity and injection of sorbent reagents.

\section{Materials and Methodology}

\section{Experimental Set-Up}

The experimental set-up (Fig. 1) was developed in order to be representative of the bag filter unit in real-scale waste incineration flue gas treatment in terms of temperature, moisture content, filtration velocity and aerosol load. The experimental device can be divided into four areas. In area one, a centrifugal fan (SC10C $0.75 \mathrm{~kW})$ supplies the setup with the laboratory air, which is previously filtered by an F9 filter (European standard EN779:2012). The airflow generated by the fan is measured with a flow meter located upstream of the latter. In area 2, the air is heated up to $70^{\circ} \mathrm{C}$ (heating collar $500 \mathrm{~W}$ ) and moistened by steam countercurrent injection (steam generator semiautomatic NEMO $1.6 \mathrm{~kW})$. The relative humidity $(\mathrm{RH})$ is measured using a capacitive hygrometer downstream of the steam injection. Area 3 corresponds to the heating zone at $150^{\circ} \mathrm{C}$ and comprises the particle injection, a straight tube (internal diameter $48.6 \mathrm{~mm}$ ) for gas flow stabilization and the filtration module (internal diameter $150 \mathrm{~mm}$ ) containing the bag filter. Particle counting is performed upstream and downstream of the bag filter using sampling probes. The whole area, namely the pipes, the filtration module and the injection and sampling probes, are heated to $150^{\circ} \mathrm{C}$ and thermally insulated to prevent condensation on the walls. The bag filter is unclogged by the pulse-jet method. During this on-line procedure, the cake is regularly removed from the filter by the injection of compressed air (at 6-7 bar) in the opposite direction to the gas flow. A removable tank collects the dust at the bottom of the filtration module. Finally, in area 4, gas condensation is ensured by means of a first multi-tube heat exchanger and a second lost-water condenser. Condensed water is collected in a tank. Finally, before being released at room temperature, the gas is filtered with an H14 filter (European standard EN1822:2009).

Tests were carried out at a constant air flow of 10 $\mathrm{Nm}^{3} / \mathrm{h}$, corresponding to a filtration velocity of $2 \mathrm{~cm} / \mathrm{s}$ at $150^{\circ} \mathrm{C}$ and $3 \% \mathrm{RH}$, and the bag filter pressure drop was measured continuously during clogging. Temperature and pressure were measured at various points in the set-up in order to calculate accurately the exact flow rates and relative humidity. The entire pilot was installed in an underpressure laboratory specialized in the study of nanoparticles with a dedicated entrance hall, and both areas 3 and 4 were placed under a ventilated hood. A gas temperature of $150^{\circ} \mathrm{C}$ was fixed in our experiments because in the gas treatment lines of real-scale waste incineration plants, the common temperature range upstream the bag filters is in between $150-250^{\circ} \mathrm{C}$, with a better reactivity of sorbent reagents reported at $150^{\circ} \mathrm{C}$. In industrial conditions, bag filter units contain several hundreds of 6-meter long bags, while 


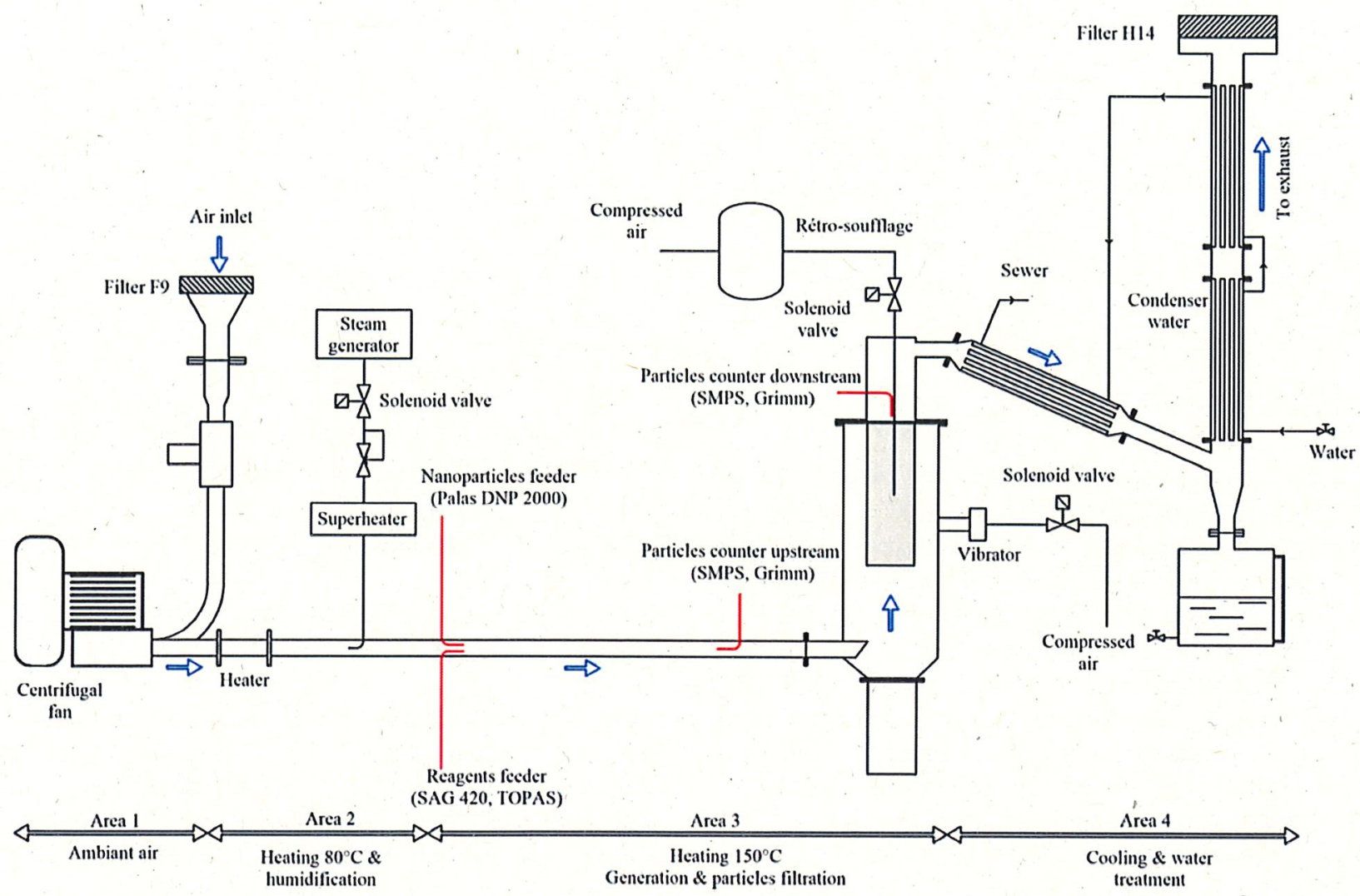

Fig. 1 Diagram of the bag filter experimental set-up

herein only a single and reduced-size bag is tested, which can be a drawback to mimic real industrial dust collectors [16].

To optimize both the operating costs and the service life of the media on real-scale plants, the bags are cleaned several times per hour on-line by pulse-jet highenergy systems in order to limit the overall pressure drop to below 2000 to $3000 \mathrm{~Pa}$. Herein, the potential drawback due to the geometry of the test equipment (one bag, geometry of the nozzle...) is limited by accurately implementing the other real application parameters assigned to mimic as closely as possible actual industrial conditions. These parameters include, implementation of a real previously used calendered PTFE fabric, the control of gas flowrate, temperature and moisture, the inlet concentrations for both the nanosized dust and the sorbent (numeric and mass concentrations, respectively), the pressure and duration of the cleaning pulse. In our lab-scale experiments the filtration time was extended until the pressure drop reached only $150 \mathrm{~Pa}$ before pulse-jet cleaning. Preliminary experimental results showed that the filter efficiency obtained during the first filtration cycle was stabilized from $90 \mathrm{~Pa}$ of pressure drop. This result guided the decision to limit the range of experimental testing to a maximum pressure drop of $150 \mathrm{~Pa}$. The aim of the study was in particular to characterize the filtration efficiency at the beginning of each filtration cycle. The performances of bag filter were studied over 11 clogging/unclogging cycles. The study characterized the filtration performances at the beginning of the bag filter lifetime before stabilization of the residual pressure drop resulting from the previous filtration cycles.

\section{Filter Characteristics}

The bag filter used in the experimental set-up was a down-sized filter with a reduced height of $0.44 \mathrm{~m}$, adapted in the laboratory from a real-scale filter provided by TREDI. The structural properties of the filter medium (thickness, fiber median diameter, porosity and basis weight) are presented in Table 1. It was a non-woven structure composed of Teflon fibers (Polytetrafluoroethylene PTFE). Figure 2 shows the surface and slice of the filter (clean medium) from scanning electron microscope (SEM) observations. The tested filter was a used unclogged bag filter previously implemented in a flue gas treatment line of waste incineration. 
Table 1 Main structural parameters of the filter medium

\begin{tabular}{|c|c|c|}
\hline Parameter & Value & Method \\
\hline Thickness $(\mu \mathrm{m})$ & $1256 \pm 31$ & $\begin{array}{l}\text { Scanning electron } \\
\text { microscope }\end{array}$ \\
\hline Fiber median diameter $(\mu \mathrm{m})$ & 19.5 & $\begin{array}{l}\text { Scanning electron } \\
\text { microscope }\end{array}$ \\
\hline Total porosity (-) & 0.64 & Mercury porosimetry \\
\hline Basis weight $\left(\mathrm{g} / \mathrm{m}^{2}\right)$ & 750 & NF EN 12127 \\
\hline
\end{tabular}

\section{Clogging Particles}

Carbon agglomerates, i.e. condensation aerosol emitted from graphite monoliths (generator DNP 2000, Palas), were used for clogging tests in order to be representative of the particle size distribution (PSD) emitted from nanowaste incineration [3, 17] or Halloysite nanotubes [18]. Reagent particles, i.e. a mixture of activated carbon and sodium bicarbonate, were generated (generator SAG 420, TOPAS) simultaneously with the carbon particles during the clogging tests, because such reagents are commonly introduced upstream of the bag filter in real-scale flue gas treatment lines for dioxin/furan and acid gas removal. The particle concentration generated was uniform over the test time at $5.45 \mathrm{E}+06$ particles $/ \mathrm{cm}^{3}$. Particles were counted with a mobility diameter particle counter (SMPS, Grimm) for the quantification of filtration efficiency during clogging tests. The PSD of the mixture of particles (carbon and reagents) upstream of the bag filter is presented in Fig. 3 , with a median diameter in electrical mobility of $45 \mathrm{~nm}$. Note that the filtration efficiency is the ratio between the number of particles collected by the bag filter and the particles upstream of the bag filter; fractional efficiency was also determined by considering the particle collection by the bag filter for each particle size range.

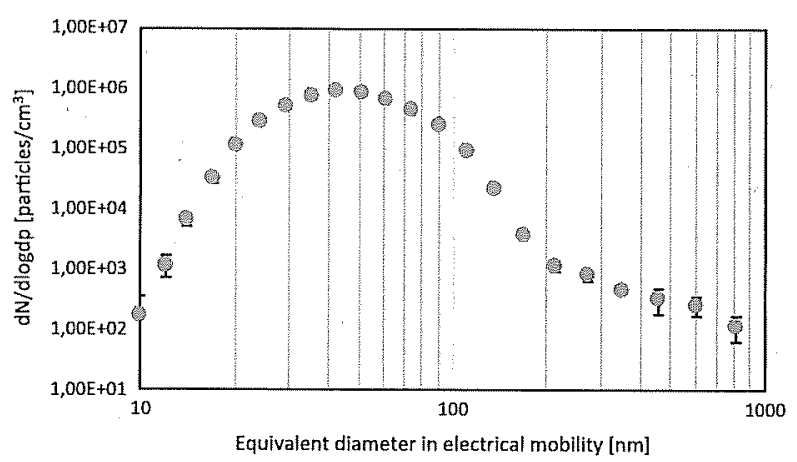

Fig. 3 Particle size distribution of the reagents and black carbon particles upstream of the bag filter at $150^{\circ} \mathrm{C}$ and $3 \% \mathrm{RH}$

\section{Results and Discussion}

\section{Bag filter Performances During Clogging/Unclogging Cycles}

Figure 4 shows the evolution of the bag filter pressure drop $(\triangle \mathrm{P})$ as a function of time over 11 successive cycles of clogging/unclogging (C1 to $\mathrm{C} 11$ ). The maximum pressure drop was set at $150 \mathrm{~Pa}$ for all filtration cycles. Once the pressure drop was reached, the filter was unclogged using the pulse-jet system. In accordance with the literature [19], the experimental results show that the clogging duration of filtration cycles decreases from the first cycle $\mathrm{C} 1$ (630 min)

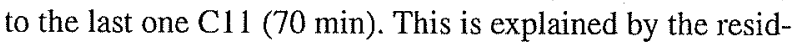
ual particulate cake from previous filtration cycles, which remains on the surface of bag filters after the cleaning operation [9]. The residual particulate cake also affects the minimum pressure drop, with the baseline corresponding to the measured bag filter pressure drop just after cleaning, which increases gradually with filtration cycles (from around 20 to $84 \mathrm{~Pa}$ ). Note that the residual cake after cleaning and the
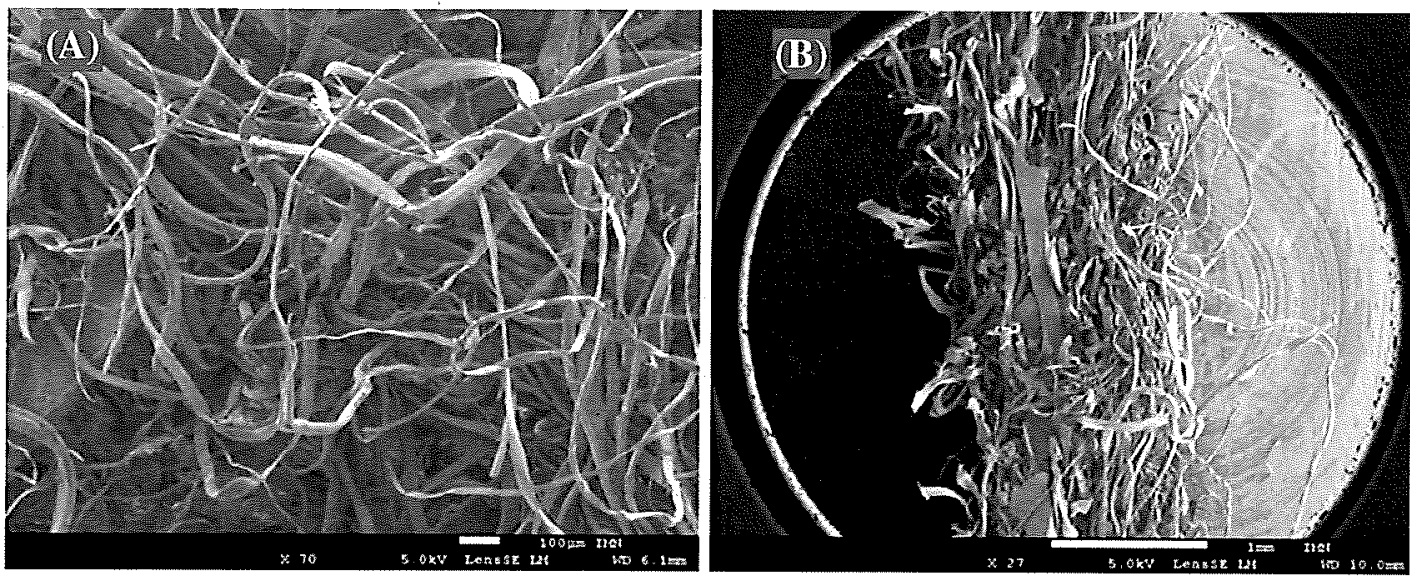

Fig. 2 SEM observations of the surface (a) and the slice (b) of the filter medium 


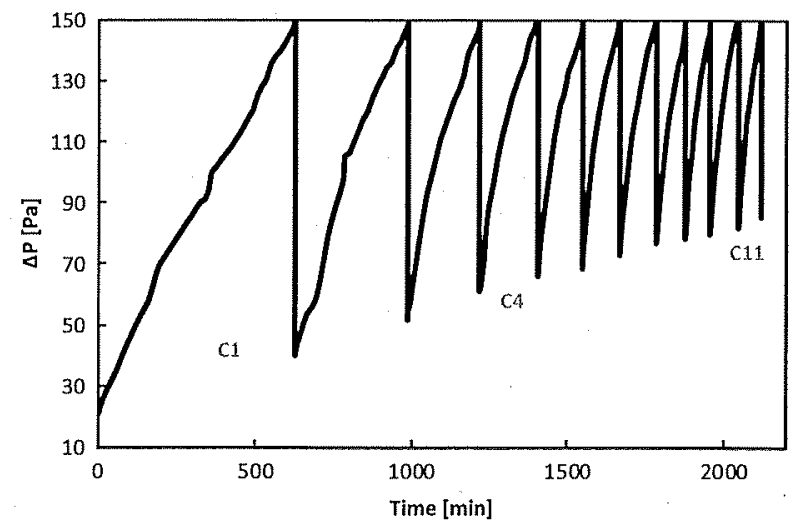

Fig. 4 Bag filter pressure drop ( $\Delta \mathrm{P})$ evolution over time for 11 clogging/unclogging cycles (from $\mathrm{Cl}$ to $\mathrm{Cl1}$ )

increasing filter pressure drop baseline are strongly dependent on the efficiency of the unclogging system.

The evolution of bag filter efficiency versus particle diameter for different values of bag filter $\Delta \mathbf{P}$ during the first clogging cycle is presented in Fig. 5. The results indicate that the minimum particle collection efficiency in the studied particle size range was $98.5 \%$. They also reveal, in accordance with the filtration theory, a gradual increase in particle collection efficiency as the filter clogs. This can be explained by the fact that the particles deposited on the filter surface are new collectors for the collection of future particles. The difference in fractional efficiency as a function of particle diameter can clearly be seen. At the beginning of clogging, three areas of particle diameter can be distinguished: (1) for small particles of $16-35 \mathrm{~nm}$, the efficiency reaches a minimum value of $99.5 \%$, (2) particles in the size range between 40 and $170 \mathrm{~nm}$ are the most penetrating through the filter, and the efficiency achieves the lowest value of $98.5 \%$ (most penetrating particle size MPPS close to $70-80 \mathrm{~nm}$ at the beginning of clogging),

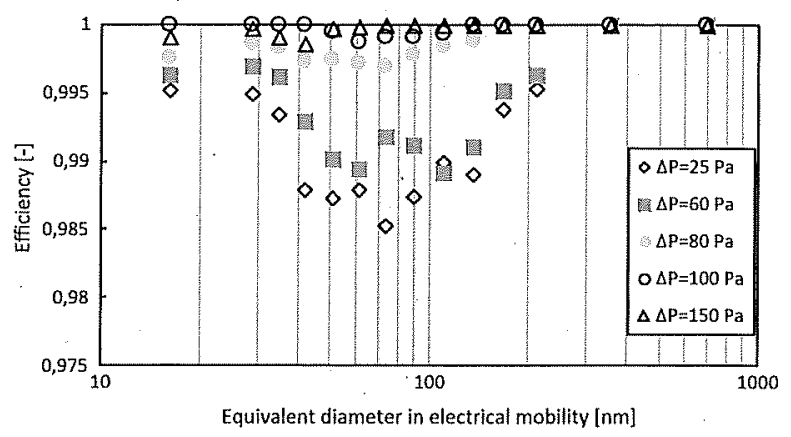

Fig. 5 Evolution of filtration efficiency as a function of particle diameter for the first filtration cycle $(\mathrm{Cl})$ at different values of filter pressure drop $\Delta \mathrm{P}$
(3) for particles in the $200-750 \mathrm{~nm}$ range, the efficiency is close to $100 \%$ even at the beginning of filtration. The collection efficiency observed for particles of $16-35 \mathrm{~nm}$ is in accordance with the results of Förster et al. [11] obtained at $150^{\circ} \mathrm{C}$ and $326 \mathrm{~Pa}$ of pressure drop. The influence of particle diameter on filtration efficiency is explained by the different filtration mechanisms responsible for fine particle collection by fibers. According to the filtration theory, there are three main mechanisms: (1) Brownian diffusion whose efficiency decreases with increasing particle diameter (2) interception, and (3) impaction, with the efficiency of the last 2 mechanisms both increasing with increasing particle diameter. For higher values of pressure drop (i.e. from $\Delta \mathrm{P}=100 \mathrm{~Pa}$ ), particle collection efficiency reaches $99.99 \%$ whatever the particle diameter.

The evolution of total efficiency with bag filter pressure drop is depicted in Fig. 6 over the first filtration cycle. Two steps may be distinguished in the figure. In the first, the total efficiency increases from $98.2 \%$ at $20 \mathrm{~Pa}$ to $99.99 \%$ at $90 \mathrm{~Pa}$. In this filtration stage, the results indicate a dependence between filter pressure drop or collected particles and filter efficiency. In the second step, the efficiency reaches around $100 \%$, whereas the pressure drop still increases with filtration.

\section{Influence of Filtration Cycles on Bag Filter Efficiency}

The evolution of collection efficiency during the filtration cycles is presented in Fig. 7 as a function of time. From the second filtration cycle $(\mathrm{C} 2)$, the results tend to reveal a gradual increase of efficiency at the pressure drop baseline (i.e. the pressure at the beginning of each cycle), especially during the filtration cycles (C2-C4). They then seem to indicate a stabilization of efficiency evolution for the last filtration cycles (C5-C11) in terms of minimum efficiency, consistent with the lower change in filter pressure drop depicted in Fig. 4. Regarding the efficiency at the end of each clogging/unclogging cycle, the values are close to

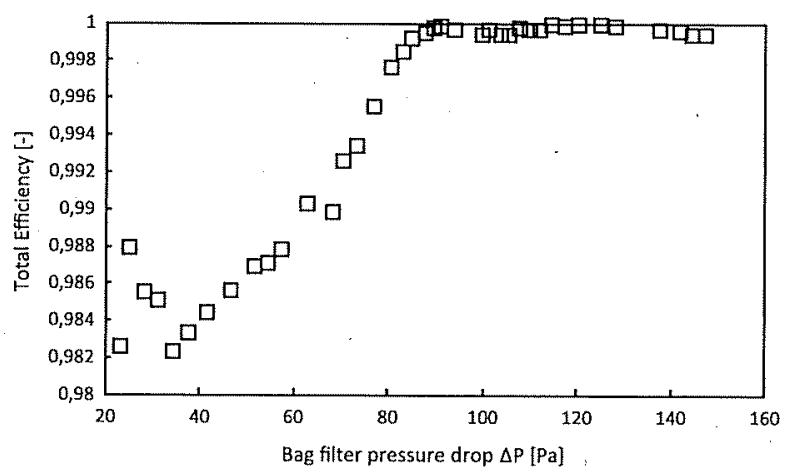

Fig. 6 Overall efficiency during the first filtration cycle 


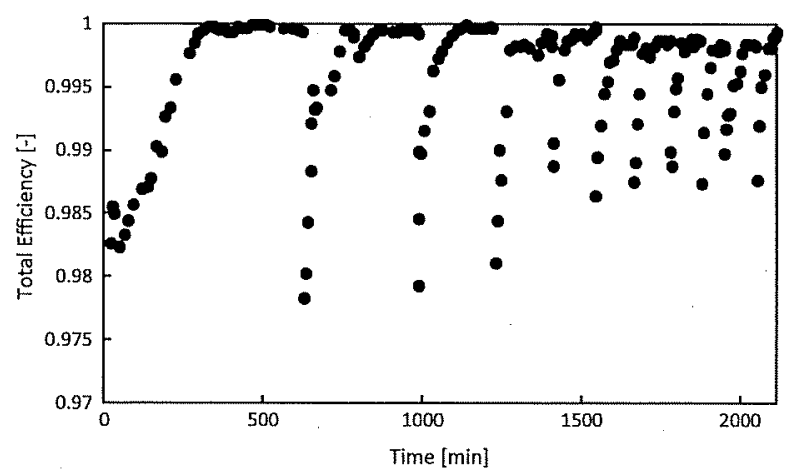

Fig. 7 Evolution of filtration efficiency during the filtration cycles

$100 \%$. However, one can notice a slight decrease of maximum collection efficiency from the filtration cycle 4 . The reason can be attributed to the residual cake remaining from the previous filtration cycles which leads to a non-homogeneous distribution of the cake thickness, and influences the distribution of pressure on the filter surface [9]. The airflow may follow preferential pathways inside the clogged filter leading to an increase of the interstitial velocity. By consequence, the effect of Brownian diffusion, which is the main mechanism responsible of nanosized particle collection, decreases with increasing of interstitial velocity. This can explain the decrease of the collection efficiency from the filtration cycle 4 (Fig. 7) and also the decrease of fractional efficiency for particles below $0.1 \mu \mathrm{m}$ (Fig. 9).

In order to examine more accurately how clogging/ unclogging cycles may affect bag filter performances, the efficiency measured at the minimum pressure drop (immediately after cleaning operations) versus particle diameter is plotted in Fig. 8 while the evolution of the efficiency measured at the maximum pressure drop of $150 \mathrm{~Pa}$ for the different filtration cycles is plotted in Fig. 9.

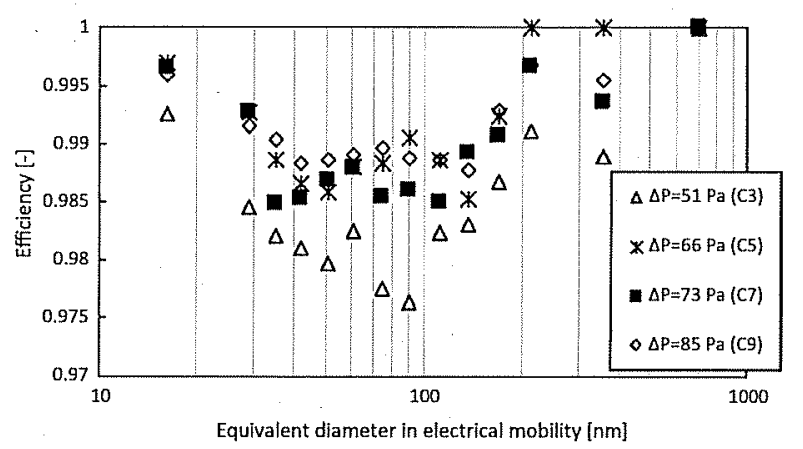

Fig. 8 Evolution of fractional efficiency measured at the minimum pressure drop for different filtration cycles as a function of particle diameter

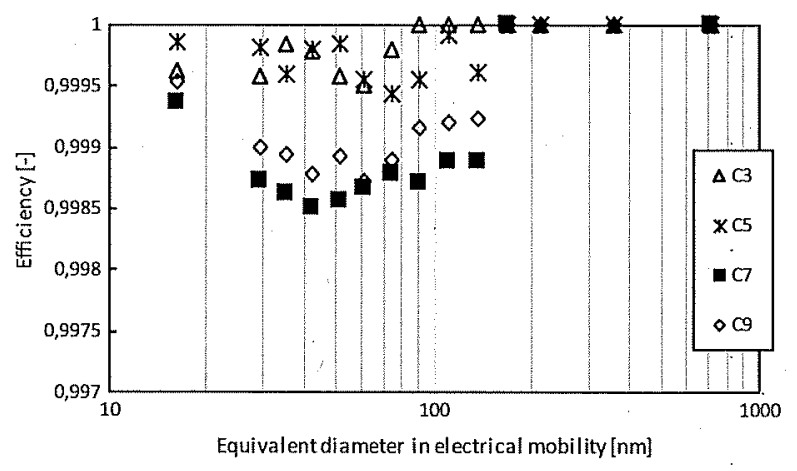

Fig. 9 Evolution of fractional efficiency at the maximum pressure drop for different filtration cycles as a function of particle diameter

Figure 8 shows that particles in the size range of 35 to $170 \mathrm{~nm}$ are the most penetrating through the filter immediately after unclogging. As a function of clogging/unclogging cycles, fractional efficiency increases slightly from 97.5 to $99 \%$ after the cleaning operation for particles in the size range of $35-170 \mathrm{~nm}$. The fractional efficiency for particles with a diameter less than $30 \mathrm{~nm}$ and above $200 \mathrm{~nm}$ is less influenced by the sequence of clogging/unclogging cycles. Note that the minimum efficiency measured in filtration cycle 3 (C3) was $97.5 \%$ against $98.5 \%$ for the first cycle (Fig. 6). This result can be explained by the fact that the structure of the bag filter surface is influenced by the cleaning system, which can affect in turn the distribution of the deposited particles after each cleaning operation. Regarding the fractional efficiency at the maximum pressure drop, the results confirm an efficiency close to $100 \%$ for all filtration cycles (between $99.85 \%$ and $99.99 \%$ ).

\section{Conclusion}

This experimental study investigated the performances of an industrial pulse-jet bag filter during submicronic and nanosized particle filtration. The evolution of the pressure drop and the efficiency was measured over 11 successive cycles of clogging/unclogging. The results confirmed that the bag filter collects nanoparticles with high efficiency ranging from 98 to $99.98 \%$. The main conclusions are:

1. The overall efficiency of the bag filter increases rapidly with clogging from a minimum value of $97.8 \%$ (cycle 2) to a maximum of $99.99 \%$.

2. The fractional efficiency varies with particle size. Three areas with significant differences in efficiency can be distinguished. Particles with a diameter of $90 \mathrm{~nm}$ are the most penetrating, for which the efficiency reaches a minimum value of $97.5 \%$ (cycle 3 ). 
3. Clogging duration decreases from $630 \mathrm{~min}$ for the first filtration cycle to around $70 \mathrm{~min}$ for the last one, as a result of the residual pressure drop increases with unclogging cycles.

\section{References}

1. Roco, M.C., Mirkin, C.A., Hersam, M.C.: Nanotechnology research directions for societal needs in 2020: summary of international study; J. Nanopart. Res. (2011). doi 10.1007/ s11051-011-0275-5

2. Fratoddi, I., Venditti, I., Cametti, C., Russo, M.V.: How toxic are gold nanoparticles? The state-of-the-art. Nano Res. (2014). doi 10.1007/s 12274-014-0697-3

3. Tran, D.T., Fleury, D., Venditti, D., Durécu, S., Joubert, A., Ounoughene, G., Meunier, T., Le Bihan, O., Le Coq, L.: The NANOFlueGas Project: Characterization and reduction of particulate emissions from the incineration of wastes containing manufactured nanomaterials. Nanosafe. SENN, Helsinki (2012)

4. Tran, D.T., Joubert, A., Venditti, D., Durécu, S., Meunier, T., Le Bihan, O., Fiani, E., Le Coq, L.: Characterization of polymer waste containing nano-fillers prior its end-of-life treatment. Biomass Valor (2016). doi:10.1007/s12649-016-9757-0

5. Schmidt, E.: Experimental investigations into the compression of dust cakes deposited on filter media. Filtr. Sep. 32, 789-793 (1995)

6. Morris, K., Allen, R.W.K.: The influence of dust and gas properties on cake adhesion in fabric filters. Filtr. Sep. 33, 334-343 (1996)

7. Koch, M., Krammer G.: The permeability distribution (PD) method for filter media characterization. Aerosol Sci. Technol. 42, 433-444 (2008)

8. Saleem, M., Krammer, G.: Effect of filtration velocity and dust concentration on cake formation and filter operation in a pilot scale jet pulsed bag filter. J. Hazard. Mater. 144, 677-681 (2007)

9. Saleem, M., Ullah Khan, R., Tahir, M.S., Krammer, G.: Experimental study of cake formation on heat treated and membrane coated needle felts in a pilot scale pulse jet bag filter using optical in-situ cake height measurement. Powder Technol. 214, 388399 (2011)

10. Saleem, M., Krammer, G., Ullah Khan, R., Tahir, M.S.: Influence of operating parameters on cake formation in pilot scale pulse-jet bag filter. Powder Technol. 224, 28-35 (2012)

11. Förster, H., Thajudeen, T., Funk, C., Peukert, W.: Separation of nanoparticles: Filtration and scavenging from waste incineration plants. Waste Manage. (Oxford). 52, 346-352 (2016)

12. Buonanno, G., Morawska, L.: Ultrafine particle emission of waste incinerators and comparison to the exposure of urban citizens. Waste Manage. 37, 75-81 (2015)

13. Cahill, P., Rasmussen, G., Tustin, M., Robertson, D.: Filtration properties of dust from fluidised bed gasification systems, pp. 111-126, Blackie, London, (1993)

14. Thomas, D., Penicot, P., Contal, P., Leclerc, D., Vendel, J.: Clogging of fibrous ${ }^{-}$filters by solid aerosol particles experimental and modelling study. Chem. Eng. Sci. 56, 3549-3561 (2001)

15. Kim, S.C., Wang, J., Emery, M.S., Shin, W.G., Mulholland, G.W., Pui, D.Y.H.: Structural property effect of nanoparticle agglomerates on particle penetration through fibrous filter. Aerosol Sci Technol. 43, 344-355 (2009)

16. Simon, X., Chazelet, S., Thomas, D., Bémer, D., Régnier, R.: Experimental study of pulse-jet cleaning of bag filters supported by rigid rings. Powder Technol. 172, 67-81 (2007)

17. Joubert, A., Tran, D.T., Le Bihan, O., Venditti, D., Durécu, S., Meunier, T., Fiani, E., Le Coq, L.: Nanowaste incineration: performances of a bag filter in a pilot scale device under real operating conditions. 5th International Conference on Engineering for Waste and Biomass Valorisation-Rio de Janeiro, Brazil (2014)

18. Ounoughene, G., Longuet, C., Le Bihan, O., Chivas-Joly, C., Motzkus, C., Debray, B., Joubert, A., Le Coq, L., Lopez-Cuesta, J.M.: Behavior and fate of halloysite nanotubes (HNTs) when incinerating PA6/HNTs nanocomposite. Environ. Sci. Technol. 49(9), 5450-5457 (2015)

19. Park, B.H., Kim, S.B., Jo, Y.M., Lee, M.H.: Filtration characteristics of fine particulate matters in a ptfe/glass composite bag filter. Aerosol Air Qual. Res. 12, 1030-1036 (2012) 